\title{
ENTRE SUBJETIVIDADES E APARATOS PEDAGÓGICOS: O QUE NOS MOVE A APRENDER?
}

\author{
RAIMUNDO MARTINS \\ IRENE TOURINHO \\ ALICE FÁTIMA MARTINS
}

\section{Resumo}

O que nos move a aprender são processos subjetivos impalpáveis, não visíveis, sensíveis, deflagrados no corpo e com o corpo. São práticas sociais e formas de relação interpessoais que plasmam percepções do 'eu' e do 'outro' formando repertórios que caracterizam nossas inserções nas diferentes comunidades das quais somos parte. As relações entre subjetividades e estruturas institucionais são pautadas por tensões que se estendem às condições formais de aprendizagem. Desejos, motivações, afetos, dúvidas, instabilidades atravessam os tempos de aprender, confrontando-se com os recursos e aparatos pedagógicos que utilizamos. A educação da cultura visual propõe tensionar e problematizar esses atravessamentos buscando estabelecer trânsitos entre sujeito e coletivo, práticas culturais e subjetividades, o imponderável e o objetivo, em vivências e experiências que nos impulsionem a questionar e seguir aprendendo como educadores e/ou como estudantes.

Palavras-chave:

Aprendizagem, corpo vivido, subjetividade, educação da cultura visual. 


\title{
SUBJECTIVITIES BETWEEN TEACHING AND PEDAGOGICAL APPARATUS: WHAT MOVE US TO LEARN?
}

\author{
RAIMUNDO MARTINS \\ IRENE TOURINHO \\ ALICE FÁTIMA MARTINS
}

\section{Abstract}

What move us to learn are intangible and invisible subjective processes set in motion in the body and with the body. Social practices and interpersonal forms of relations shape our perceptions of 'self' and 'other' constructing repertoires that characterize our insertions in the different communities in which we are part. The relations between subjectivity and institutional structures are guided by tensions which extend themselves to the formal conditions of learning. Desires, motivations, affects, doubts and instabilities trespass the timings of learning when being confronted with the resources and pedagogical apparatuses we utilize. Visual culture education proposes to tension and problematize these various trespassing trying to establish transits between subject and collectivity, cultural practices and subjectivities,

Keywords: Learning, lived body, subjectivity, visual culture education. the thoughtless and the objective, through living experiences which animate us to question and to continue learning as educators and/or students. 
Os

propósitos pedagógicos que nos mobilizam como docentes e que buscamos desenvolver com os alunos não devem ser apenas amostras das nossas convicções filosóficas ou retalhos das teorias de aprendizagem da nossa preferência. Tais propósitos devem, principalmente, expressar aquilo que somos, da maneira como vivemos o cotidiano da sala de aula, dos modos e gestos que identificam nosso corpo, nossa voz, nosso jeito de ver o mundo, enfim, nossas ideias, nossa mente, nossos afetos.

Aprendizagens acontecem por meio de processos subjetivos que não são visíveis, tampouco são palpáveis. Acontecem no corpo e com o corpo, envolvendo práticas sociais aprendidas em contexto, formas de relação instaladas no nosso modo de ser e viver e, portanto, já fazem parte do nosso repertório cotidiano de participação em diferentes comunidades. Esses processos subjetivos se caracterizam claramente como um 'paradoxo' diante do arsenal de recursos e aparatos pedagógicos, conteúdos e modalidades de avaliação que nos sitiam e nos acossam em nome de uma "objetividade" institucional/ oficial que prescreve aprendizagens operacionais, comportamentais, funcionais e sazonais.

Os tempos de aprender não são, necessariamente, os tempos de programações curriculares que prescrevem o quê, quando e como aprender. Os tempos de aprender estão atravessados por desejos, expectativas, dúvidas, inseguranças e afetos que pertencem aos tempos e bagagens dos sujeitos, mediados pelas subjetividades que produzem, mas, sobretudo, pelas práticas sociais que os enredam. Como explica Ellsworth (2005, p. 2), o tempo dos sujeitos está repleto de "movimentos, sensações e afetos" que os mobilizam para "estar contínua e radicalmente em relação com o mundo, com os outros e com o que fazemos com eles" (p. 4). A autora detalha ao mesmo tempo em que desconstrói esse processo de maneira simples e pedagógica: 
A aprendizagem nunca acontece na ausência de corpos, emoções, lugar, tempo, som, imagem, auto experiência, história. Sempre se desvia através da memória, dos esquecimentos, o desejo, o medo, o prazer, a surpresa, a reescritura. Porque a aprendizagem sempre acontece em relação, seus rodeios nos levam até e, às vezes, através dos limites do hábito, o reconhecimento e as identidades socialmente construídas que habitamos. A aprendizagem nos leva até e através das fronteiras entre nós e os outros e através do lugar da cultura e o tempo da historia (ELLSWORTH, 2005, p. 53).

Por esta razão, podemos dizer que a educação da cultura visual, além de ser uma atitude aberta em relação ao mundo, a sociedade, ao outro, e às práticas culturais, é, sobretudo, uma "metodologia viva" (HERNÁNDEZ, 2013) que nos impulsiona a questionar e seguir aprendendo, nos aproxima daqueles pensamentos que nos movem, colocam em xeque nossas verdades e nos auxiliam a encontrar caminhos para responder nossas interrogações. Esses trânsitos e deslocamentos nos ajudam a "impedir a 'paralisia' das informações que produzimos e que precisamos descrever-analisar. Movimentam-nos, em síntese, para multiplicar sentidos, formas, lutas" (MEYER; PARAÍSO, 2012, p. 17).

\section{Aprendendo com imagens}

Esse jeito de pensar ajuda-nos a ensaiar outras formas de compreender os artefatos culturais, a renovar modos de indagar e analisar, compartilhando perspectivas pedagógicas que potencializem o ato de fazer e de criar, aprender e ensinar, intensificando nossos diálogos com os desafios políticos, econômicos, culturais e educacionais do tempo que estamos vivendo.

Analisar imagens e artefatos visuais para compreender sua significação cultural, pressupõe identificar e destacar a dimensão social da própria imagem explorando as relações de poder inerentes ao contexto no qual foram produzidos. Como elementos simbólicos, imagens e artefatos visuais suscitam/articulam possíveis diálogos com receptores ou audiências e, em consequência, as circunstâncias e resultados da sua circulação.

Tanto a interpretação quanto os significados das imagens são impensáveis se não estiverem em relação com outras imagens. As imagens e, especialmente, as imagens em movimento, possuem "potência para romper com e ressignificar 
determinadas construções sociais [artísticas e pedagógicas] já existentes" (FISCHER; MARCELLO, 2011, p. 511). Ruptura e ressignificação são aspectos importantes no trabalho pedagógico com imagens porque apontam para a necessidade de aceitarmos a pluralidade de posições e interpretações existentes, os diferentes matizes que plasmam nossas formas de ver o mundo da escola e a realidade social e de buscar entender a subjetividade de aprendizes e professores. Refletir sobre a pluralidade, além de ressaltar as diferenças pessoais, ajuda a respeitar e aprender com as experiências, posições e saberes do 'outro', valorizando o ato da 'escuta', dimensão importante na formação e desenvolvimento da subjetividade. As possibilidades de experiências educativas com imagens são múltiplas, seus significados dinâmicos e plurais, mas, muitas vezes, conflitivos. Em contraposição à pluralidade e o valor da escuta, "nosso olhar é sempre contingente, datado, limitado pelas posições de sujeito que ocupamos e por fatores que desconhecemos" (MEYER; PARAIISO, 2012, p. 89).

Esses temas e discussões caracterizam a educação da cultura visual como uma abordagem transdisciplinar que se fundamenta e põe em perspectiva conceitos de descontinuidade, deslocamento, instabilidade e mutabilidade. Estes princípios orientam os movimentos pós-modernista e pós-estruturalista. Contrapondo-se às concepções e práticas pedagógicas herdadas do modernismo, reivindicam a necessidade de mudança na maneira de pensar a imagem, a sociedade e suas instituições, buscando atender às novas condições socioculturais e estéticas que passaram a configurar o mundo contemporâneo.

Ao discutir a fragmentação do sujeito e sua historicidade, a perspectiva pós-estruturalista enfatiza a necessidade de analisar, nas práticas institucionais e pedagógicas, "os processos pelos quais se formam e se alteram [esses] fragmentos em cada um de nós e como eles se relacionam entre si e com os fragmentos dos outros" (VEIGA NETO, 2004, p. 55). Fragmentação e historicidade são elementos geradores de tensão que nos ajudam a compreender os processos de produção de subjetividade, a maneira como esses processos interatuam, como nos interpelam e nos confrontam, mobilizando-nos para refletir e ver a partir de outras posições que se diferenciam ou se contrapõem às concepções e comportamentos pedagógicos que carregamos. Esse tipo de trabalho analítico deixa evidente a necessidade de um permanente exercício de reflexão sobre as nossas escolhas pedagógicas, a nossa capacidade de rever 
e reelaborar estratégias de aprendizagem, mas, sobretudo, sobre a nossa capacidade de flexibilizar as formas de dialogar com a experiência visual dos alunos, tratando seus repertórios de imagens e artefatos visuais como trânsitos entre cultura, visualidade, docência e educação.

Experiências com imagens são registros de concepções, visões de mundo que apontam para universos simbólicos onde estão abrigados desejos, ideias, fragilidades, conceitos, tristezas/decepções e prazeres. Esses universos constituídos por imaginários individuais e coletivos, preferências emocionais e afetivas, são protegidos por "filtros produzidos pelas nossas histórias/trajetórias pessoais e pela cultura" (TOURINHO; MARTINS, 2011, p. 60).

Nesse sentido, as

imagens que vemos são vestígios dessa realidade, resultado de um trânsito, uma transferência de informações/eventos visuais entre o mundo externo e o mundo da mente/corpo. Essa transferência de informações e eventos visuais agrega um processo de estabilização que, apesar dos lapsos de tempo que os caracterizam e distinguem - seleção, diferenciação, omissão, foco, enquadramento etc. -, dá sentido e continuidade ao que é visto como unidades separadas, ou seja, como fragmentos imagéticos. (TOURINHO; MARTINS, 2011, p. 6o)

Assim, ao nos deixarmos guiar por referências visuais canonizadas, acervos imagéticos estabelecidos e legitimados, sem considerar o repertório e as experiências visuais dos estudantes, funcionamos por meio de disposições naturalizadas, sem nos preocupar em criar espaços de diálogo, ou seja, sem buscar compreender onde eles (estudantes), e nós (professores), situamos/localizamos nossos modos de ver e compreender nossas relações pedagógicas com o mundo, com a aprendizagem, com a escola, com o conhecimento. Ao desconsiderar esse processo de reflexividade que nos ajuda a tomar consciência da posição de onde falamos e, ao mesmo tempo, a experienciar outros modos de ver, reduzimos nossa curiosidade de aprender com a experiência do 'outro', neste caso, a experiência dos estudantes. Adicionalmente, desmobilizamos atitudes e interesses sobre outras possibilidades de aprender sobre o nosso cotidiano, o cotidiano da escola e dos estudantes. 


\section{Pensando pedagogias entre aparatos visuais e fronteiras}

Aronowitz e Giroux (1991, p. 140) explicam que a teoria pós-moderna destruiu a estabilidade das disciplinas assim como a ideia ilustrada de conhecimento baseada em "cimentos irrefutáveis que são pontos de partida irredutíveis para toda investigação" e, em consequência, para os processos de aprender e ensinar. De acordo com estes educadores, o conhecimento deve ser tratado como parte de um aparato institucional em seus contextos de poder, e as relações entre docentes, discentes e suas trajetórias devem ser abordadas como lugares onde diferentes significados e formas de produção cultural acontecem configuradas por práticas dialógicas passíveis de conflito e contestação.

A ideia de uma epistemologia de fronteira

aponta para um tipo diferente de poder, múltiplo, em grande parte transdisciplinar e significativamente 'aberto', uma vez que o objetivo é o de manufaturar novas formas de análise, não só de contribuir para sistemas de pensamento estabelecido (DIAS, 2011, p. 89).

Acompanhando o pensamento do autor e também fazendo uma analogia, podemos dizer que o conceito de pedagogia de fronteira "surge das condições de se teorizar [e pensar pedagogicamente] a partir da fronteira" (...), "como uma atividade de descolonização do conhecimento situado nos subalternos" (...), como conceito, conhecimento e pensamento pedagógico que provocam um "deslocamento de rígidas noções de expectação, análise de imagens, modos de ver, questões de posicionalidade, epistemologia, poder, identidade, subjetividade, agência e vida cotidiana (DIAS, 2011, p. 89).

Tais mudanças tem impacto nas relações pessoais, nas experiências de vida e nos espaços simbólicos dos indivíduos, interferindo e até mesmo modificando práticas culturais, deixando marcas nas posições discursivas que organizam nossos modos de pensar e compreender o mundo e a instituição escolar. Essa força subjetiva, de acordo com Braidotti (2000), nos posiciona como sujeitos nômades e é algo que se constrói cotidianamente a partir de múltiplas referências, relações e experiências. Ao explicar o modo como essa força subjetiva medeia as relações intra e interpessoais, Braidotti (2000, p. 8o-81) esclarece que 
Deixar que outros falem em meu texto não é apenas uma maneira de inscrever meu trabalho em um movimento político coletivo, mas, também, um modo de praticar o que digo (...). Deixar que as vozes de outros ressoem no meu texto é, pois, um modo de tornar realidade a ideia de deslocar o 'eu' do centro do projeto de pensamento e somá-lo a um projeto coletivo.

Processos de subjetivação funcionam como pontes que tornam acessíveis nossas experiências pessoais e profissionais. Esses processos podem ser ampliados para alcançar e incluir pessoas de nosso círculo familiar, amigos e pessoas com quem convivemos no ambiente de trabalho. Esse descentramento abre outras perspectivas para abordar as relações imagem-receptor, professor-estudante, aprendizagem-aprendiz, alertando-nos para o fato de que a compreensão dos significados depende das circunstâncias, dos episódios e da maneira como percebemos e assimilamos relações. Esta mudança no modo de construir e entender o conhecimento proporciona uma visão crítica sobre os métodos de investigação, de aprendizagem e, principalmente, sobre saberes e fazeres entretecidos na escola.

Aprofundando um pouco mais a discussão, podemos dizer que processos de subjetivação provocam instabilidades conceituais, abrindo espaço para deslocamentos que nos ajudam a rever, reelaborar e redimensionar ideias, convicções e mesmo crenças que acalentamos como verdades estabelecidas, silenciosamente/tacitamente radicadas nas nossas experiências como parte do nosso repertório visual e da nossa prática docente. Fazendo uma analogia com os argumentos expostos por Fresquet (2007), as imagens, sejam elas de arte, de publicidade, de informação, de entretenimento, podem nos ajudar a retomar nossas próprias experiências revisitando-as a partir de outras perspectivas, outros pontos de vista e posicionamentos, acionando dispositivos para desativar ou desaprender certas práticas profissionais e acadêmicas, para criar mudanças nas nossas relações pessoais, sociais, culturais e pedagógicas.

\section{De identidades e subjetividades aos tempos de aprender}

Desde muito cedo convivemos com imagens. Nascemos e crescemos cercados por elas. Outdoors, televisão, computadores, videogames, internet, celulares, filmes, animações, brinquedos - todos esses aparatos veiculam, produzem, fazem uso de ou são imagens. Aos poucos, essas imagens vão 
consolidando sentidos, determinando valores e significados de maneira quase imperceptível. Não nos damos conta disso. Quando começamos a perceber o efeito dessas interações com o mundo imagético, essas influências já estão evidentes no comportamento de crianças, adolescentes, jovens, e, sem dúvida, de adultos.

É importante compreender a diferença entre identidade e subjetividade. A identidade não é resultado da nossa escolha. Não escolhemos nascer homem ou nascer mulher, da mesma forma que não escolhemos nascer em uma família católica, protestante ou de qualquer outro credo. A classe social na qual nascemos também não é fruto da nossa opção. Da mesma forma, também não escolhemos frequentar determinados ambientes e escolas. Quando nos damos conta ou quando começamos ter alguma noção/consciência da nossa condição, já somos parte de um núcleo familiar, frequentando determinados lugares e instituições, cultivando certos valores e incorporando todas essas influências.

A identidade envolve questões muito complexas. Durante muito tempo pensamos que a identidade, esse conjunto de características próprias e exclusivas que nos diferencia de outras pessoas, era uma coisa fixa. Tínhamos a convicção de que nascemos de um jeito, com certas tendências e características que vão se confirmando à medida que crescemos e, fatalmente/ inevitavelmente, continuamos daquele jeito na idade adulta. Esta crença se alastrou se transformando num tipo de compreensão do mundo social que denominamos senso comum. Ainda hoje, essa crença reverbera sua força num ditado popular muito conhecido: pau que nasce torto, não tem jeito, morre torto!

Hoje, revisamos a noção de identidade. Compreendemos que se trata de uma referência plural por princípio. Identidades, sendo múltiplas, são também mutantes. Por exemplo: no momento em que estamos escrevendo este texto, pensamos e agimos como pesquisadores. Interrompida essa atividade, cada um de nós pode dirigir-se a outros campos. Por exemplo, enquanto um vai ao encontro da esposa, da filha, outra busca pelo irmão, ou atende o telefonema de um amigo. Cada qual em seus respectivos contextos, nas diversas dessas situações, assume papéis distintos, ocupando posições diferentes da de pesquisadores, com preocupações e atenções outras, quais sejam tarefas domésticas, contas a pagar, planos e projetos futuros, entretenimento, relações filiais, paternais, maternais, fraternas... 
Em curtos períodos de tempo, passamos por situações e circunstâncias sociais nas quais desempenhamos, simultaneamente, diferentes papeis, funções e responsabilidades sociais, familiares e profissionais, todas evocando identidades referenciais diversas. É como se a cada momento possamos operar em diferentes tipos de frequência sócio-cultural-subjetiva. Por vezes, precisamos operar simultaneamente em diferentes frequências.

Talvez possamos dizer que as identidades são modos de performances culturais, formas de comportamento que atendem/cumprem funções sociais. Algumas delas acontecem em tempos, faixas etárias e locais definidos, em espaços públicos ou privados. Outras estão circunscritas a espaços comunitários, práticas familiares e situações de intimidade. Mas, muitas vezes, elas se miscigenam, hibridizam, subvertendo categorias e territórios. A adolescente que é mãe solteira, o marido ou a esposa surpreendidos com um/a amante, são exemplos de possíveis e frequentes atravessamentos identitários. As identidades, sendo múltiplas, compõem o que chamamos de personalidade, ou temperamento, características psicológicas que definem nossos modos de pensar, sentir e agir. As identidades configuram, também, os modos como vemos o mundo, como nos relacionamos com ele e com as pessoas com as quais convivemos.

Como dissemos anteriormente, não escolhemos nossas identidades, elas estão sendo permanentemente formadas ou, nos formando. Por isso é difícil lidar com elas, porque envolvem relações diversificadas, complexas e delicadas. Mas a subjetividade está, de alguma maneira, ao nosso alcance. Podemos agir sobre ela nos auto-observando, nos ajudando, buscando um modo de nos transformar em indivíduos melhores. Por esta razão as pessoas fazem análise, vão ao terapeuta, se convertem a outras religiões ou se associam a elas, enfim, buscam ajuda. A subjetividade tem esse caráter operacional que nos torna passíveis de transformação.

Essa é uma função importante do professor: deixar de lado o tabu da objetividade como meta ou a expectativa de ser objetivo como sujeito, como docente, como aprendiz. A subjetividade nos faz solidários, nos faz cúmplices de nós mesmos e do outro (colega, aluno), mas, sobretudo, nos faz humanos. Nesse sentido, a subjetividade tem um papel importante na formação docente e na prática pedagógica ao colocar em perspectiva as implicações da relação identidade-subjetividade e a necessidade de desenvolvermos uma compreensão crítica desses processos. 
Nas últimas décadas, questões referentes à identidade e a subjetividade tem sido foco de discussões educacionais, políticas, institucionais e pedagógicas, por tratar-se de matrizes complexas, que medeiam ao mesmo tempo em que expõem e contrapõem particularidades e práticas específicas utilizadas como estratégias de resistência ou de afirmação nas instituições de ensino. Culturas das imagens, culturas do entretenimento, culturas escolares, culturas digitais e culturas visuais são alguns dos exemplos de mestiçagens conceituais abertas, plasmadas por formas visuais e conceituais híbridas que nos assediam cotidianamente e que buscamos compreender. São formas cambiantes, formas mutantes de modalidades identitárias provisórias, oriundas de, ou expostas a nomadismos culturais dependentes dos processos de mundialização que habitam o panorama contemporâneo. Essas formas trazem no seu bojo questões antropológicas, políticas, tecnológicas, educacionais e pedagógicas que nos defrontam e nos desafiam. O desafio está posto: de alguma maneira, ou em alguma medida, temos que aprender a lidar com elas.

\section{Referências}

ARONOWITZ, Stanley; GIROUX, Henry. Postmodern education: politics, culture and social criticism. Minneapolis: University of Minnesota Press, 1991.

BRAIDOTTI, Rosi. Sujetos nómades: corporización y diferencia sexual en la teoría feminista contemporánea. Buenos Aires, Argentina: Paidós, 2000.

DIAS, Belidson. O I/Mundo da educação em cultura visual. Brasília: Programa de Pós-Graduação em Arte da Universidade de Brasília, 2011.

ELLSWORTH, Elizabeth. Places of learning: media, architecture, pedagogy. Nova York: Routledge, 2005.

FISCHER, Rosa Maria Bueno; MARCELLO, F. de A. Tópicos para pensar a pesquisa em cinema e educação. Educação e Realidade, v. 36, n. 2, 'p. 505-519, maio/agosto 2011.

FRESQUET, A. Imagens do desaprender: uma experiência de aprender com cinema. Rio de Janeiro: Editora da UFRJ, 2007.

HERNÁNDEZ, Fernando. Pesquisar com imagens, pesquisar sobre imagens: revelar aquilo que permanece invisível nas pedagogias da cultura visual. In: MARTINS, Raimundo; TOURINHO, Irene (Orgs.). Processos e práticas de 
pesquisa em cultura visual e educação. Santa Maria: Editora UFSM, 2013.

MEYER, Dagmar E.; PARAÍSO, Marluce A. Metodologias de pesquisas pós-críticas em educação. Belo Horizonte: Mazza Edições, 2012.

VEIGA NETO, Alfredo. Olhares. In: COSTA, Marisa Vorraber (Org.). Estudos culturais em educação. Porto Alegre: Editora da UFRGS, 2004, p. 37-72.

TOURINHO, I.; MARTINS, Raimundo. Circunstâncias e ingerências da cultura visual. In: MARTINS, Raimundo; TOURINHO, Irene (Orgs.). Educação da cultura visual: conceitos e contextos. Santa Maria: Editora da UFSM, 2011.

Recebido em: 07/10/2013

Aceito em: 08/ 11/2013 


\section{RAIMUNDO MARTINS}

raimundomartins2005@yahoo.es

Professor titular da Faculdade de Artes Visuais e docente do Programa de Pós-Graduação em Arte e Cultura Visual. É Editor da "Coleção Desenredos" e membro dos Grupos de Pesquisa Cultura Visual e Educação (UFG), Arte, Educação e Cultura (UFSM), Laboratório Imagem \& Educação (UERJ). Em 2013 publicou - com Irene Tourinho - o livro "Processos \& Práticas de Pesquisa em Cultura Visual \& Educação".

\section{IRENE TOURINHO}

irenetourinho@yahoo.es

Professora titular aposentada da Faculdade de Artes Visuais e do Programa de Pós-Graduação em Arte e Cultura Visual. É membro dos Grupos de Pesquisa Cultura Visual e Educação (FAV/UFG), Arte, Educação e Cultura (UFSM), Laboratório Imagem \& Educação (UERJ). Em 2013 publicou - com Raimundo Martins - o livro "Processos \& Práticas de Pesquisa em Cultura Visual \& Educação".

\section{ALICE FÁTIMA MARTINS}

profalice2fm@gmail.com

Pós-Doutora em Estudos Culturais (PACC/UFRJ), Doutora em Sociologia (UnB). Professora na Faculdade de Artes Visuais (FAV/ UFG), no curso de Licenciatura em Artes Visuais, e no Programa de Pós-Graduação em Arte e Cultura Visual, do qual é Coordenadora. Publicou os livros Catadores de Sucata da Indústria Cultural, pela Editora da UFG (2013) e Saudades do Futuro: a ficção científica no cinema e o imaginário social sobre o devir, pela Editora da UnB (2013). 